\title{
Uncommon causes of chronic cough associated with airway eosinophilia
}

\author{
Jiaxing Xie ${ }^{1}$, Kian Fan Chung ${ }^{2}$, Kefang Lai ${ }^{3}$ \\ ${ }^{1}$ Department of Allergy and Clinical Immunology, National Clinical Research Center for Respiratory Disease, State Key Laboratory of Respiratory \\ Disease, Guangzhou Institute of Respiratory Health, the First Affiliated Hospital of Guangzhou Medical University, Guangzhou, China; ${ }^{2}$ National \\ Heart and Lung Institute, Imperial College London, Royal Brompton and Harefield NHS Foundation Trust, London, UK; ${ }^{3}$ National Clinical \\ Research Center for Respiratory Disease, State Key Laboratory of Respiratory Disease, Guangzhou Institute of Respiratory Health, the First \\ Affiliated Hospital of Guangzhou Medical University, Guangzhou, China \\ Correspondence to: Prof. Kefang Lai. National Clinical Research Center for Respiratory Disease, State Key Laboratory of Respiratory Disease, \\ Guangzhou Institute of Respiratory Health, the First Affiliated Hospital of Guangzhou Medical University, 151 Yanjiang Road, Guangzhou 510120, \\ China. Email: Klai@163.com.
}

Submitted Jun 29, 2020. Accepted for publication Feb 21, 2021.

doi: $10.21037 /$ jtd-20-2324

View this article at: http://dx.doi.org/10.21037/jtd-20-2324

Chronic cough is defined as the sole or predominant symptom and lasting for more than 8 weeks, with a normal chest X-ray (1). The four common causes of chronic cough are cough-variant asthma (CVA), non-asthmatic eosinophilic bronchitis (NAEB), upper airway cough syndrome (UACS) and gastroesophageal reflux disease (GERD) (2).

Eosinophilic airway inflammation, which is observed in $30 \%$ to $50 \%$ of chronic cough patients, is a common feature of CVA, NAEB and UACS. The response to corticosteroid therapy in these patients is generally very good (3). CVA, an airway disorder characterized by type 2 -driven inflammation, is considered the most common cause of chronic cough (4). NAEB, another common cause of chronic cough, is characterized by airway eosinophilic inflammation without airway hyperresponsiveness (5). Previous studies F $(6,7)$ have shown that the Th2 pathway also plays a role in NAEB.

However, eosinophilic infiltrates in the airways, blood eosinophilia and chronic cough may be the main characteristics of other conditions, that do not respond to corticosteroid therapy. Type 2-driven inflammation does not appear to be the main mechanistic pathway underlying eosinophilic airway inflammation. Making a clear diagnosis, controlling eosinophilic airway inflammation and managing cough can be difficult. In this editorial commentary, we describe (I) the possible uncommon causes of chronic cough associated with airway eosinophilia, (II) management of these uncommon causes of chronic cough and (III) mechanistic insights linking eosinophilic airway inflammation and cough. These uncommon conditions include (i) hypereosinophilic syndrome (HES), (ii) IgG4-related disease (IgG4-RD), (iii) Occupational eosinophilic bronchitis.

\section{HES}

HES is defined as unexplained sustained peripheral blood eosinophilia ( $>1,500$ cells $/ \mathrm{mL}$ for longer than 6 months) with evidence of organ damage due to eosinophilic infiltration but not other causes (8). HES can be categorized as primary (neoplastic) HES, secondary (reactive) HES, and other variants of HES (e.g., familial) (8). HE-related organ damage can occur in the upper and lower airways, lung and other organs $(8,9)$. We reviewed the literature and found reports of eight cohorts of HES patients consisting of 411 cases (10). Lung involvement ranged from $25 \%$ to $67 \%$ $(37.77 \%)$, with the incidence of cough ranging from $10 \%$ to $41 \%(23.11 \%)$. HES may be a rare and long-ignored cause of chronic cough. Most studies on blood eosinophilia and chronic cough have focused on primary HES.

Chronic cough associated with HES has been associated particularly with presence of the FIP1L1-PDGFRA fusion 
gene (11). Recently, we reported (10) 2 patients with HES, eosinophilic airway inflammation, bronchial hyperreactivity and chronic cough, among which one was PDGFRA+, but the second patient was PDGFRAHES with features suggestive of myeloproliferative neoplasm (MHES) $(12,13)$. Both cases had been previously misdiagnosed as CVA and failed to respond to anti-asthma treatment, including corticosteroid therapy. The patients' severe prolonged cough and hypereosinophils levels were successfully cured with imatinib. We had reviewed the literature and summarized nine cases of PDGFRA+ HES with chronic cough as the main or sole manifestation (10). The cause of cough in HES and FIP1L1-PDGFRA fusion gene or MHES patients may be associated with thickening of the basement membrane, goblet cell hyperplasia, airway eosinophilic inflammation or active mast cells $(14,15)$. No allergic or nonallergic pathways seem to contribute to its pathogenesis. A molecular defect in the eosinophil lineage itself drives abnormal eosinophil expansion and activation (16). Then, the eosinophils migrate to the airway. It is unknown why only a minority of PDGFRA+ HES or MHES patients show involvement of the airway. The mechanisms underlying eosinophilic airway inflammation and bronchial hyperreactivity warrant further investigation. Therefore, we suggest a screen for the FIP1L1-PDGFRA fusion gene, particularly when only cough or other nonspecific symptoms are present in subjects with blood eosinophilia. For the patients with severe eosinophilia who are negative for the FIP1L1PDGFRA fusion gene, a possible diagnosis of MHES should be considered when patients have splenomegaly, elevated serum B12, and/or Tryptase levels, and resistance to corticosteroid therapy.

\section{IgG4-RD}

Recently, we treated a patient with HES, eosinophilic airway inflammation and chronic cough, that was associated with high IgG4 levels. We report this case and reviewed all published cases in the literature in order to learn more about the features of IgG4-RD-associated cough and to determine how different from PDGFRA+ HES associated cough. Written informed consent was obtained from the patient for publication of this case report.

The patient was a 65 -year-old male non-smoker who complained of sneezing, itchiness and a blocked or runny nose in March 2019. The symptoms usually started soon after exposure to cold air and improved after he took loratadine. He had no allergies, history of atopy or family asthma/atopy history. He then began to have nocturnal dry cough and was admitted to the respiratory ward of a local tertiary hospital last July with a complaint of chronic cough for 2 months. No dry rales were heard. His fractional exhaled nitric oxide (FeNO) level was $275 \mathrm{ppb}$, Total $\mathrm{IgE}$ was $495 \mathrm{IU} / \mathrm{mL}$, and the patient was positive for dust mite IgE. Blood eosinophils were $4,480 / \mu \mathrm{L}$ and $43.4 \%$. Lung fields were normal on chest radiograph. Nasal topical corticosteroids, inhaled corticosteroids (ICS), long-acting beta2-agonists, antihistamines and $8 \mathrm{mg}$ of oral methylprednisolone significantly improved his symptoms. He was diagnosed with allergic rhinitis and CVA and discharged on 12 July 2019. Ten days after discontinuation of oral corticosteroid, his nocturnal dry cough recurred. Moreover, he began to exhibit dyspnoea, wheezing, fatigue, bitter taste, decreased appetite, moderate but poorly localized abdominal pain and distension. Painless purpura was noticed in the lower limbs. He was admitted again and followed up in that hospital. During the follow-up, he presented progressing blood eosinophilia of 2,100-3,600-5,400 eosinophils/ $\mu \mathrm{L}$, serum creatinine of 78-105-139 $\mu \mathrm{mol} / \mathrm{L}$, and direct bilirubin of $17.2-28-37.5 \mu \mathrm{mol} / \mathrm{L}$; IgG of $22-38 \mathrm{~g} / \mathrm{L}$; and decreasing haemoglobin of 117-104-99 g/L. Antinuclear antibodies and rheumatoid factors were positive. After one week of prednisone (40 mg daily) treatment, he was transferred to our hospital. Parasite infection, multiple myeloma, PDGFRA+ HES, MHES, lymphoma and other malignancies were excluded by PET-CT, bone marrow examination and other investigations. The patient's FeNO was $219 \mathrm{ppb}$, and the sputum eosinophil percentage was $39 \%$. The FEV1\% was $117 \%$, and the bronchial challenge test (Mch PD20 of $0.311 \mathrm{mg}$ ) was positive. The IgG4 level was very high at a level of $27.1 \mathrm{~g} / \mathrm{L}$ (normal range, 0.08 to $1.4 \mathrm{~g} / \mathrm{L}$ ). In kidney biopsy, plasma cells, eosinophils and lymphocytes inflammatory infiltrates were prominent. Immunohistochemical studies showed mixed mononuclear inflammatory cells, with $15 \%$ staining positive for IgG4. No small vessels or artery vasculitis was observed. This patient's clinical features (elderly; male; symptoms of chronic cough, abdominal pain and fatigue) and the results of investigation (enlarged submandibular glands, progressive elevated IgG and bilirubin, high IgG4, kidney biopsy) were consistent with IgG4-RD, although some features were atypical. A high dose of ICS was given. He was 
referred to a hospital in Macau, China, to receive antiIL-5-R $\alpha$ treatment with benralizumab. He recovered very quickly from this treatment with relief of his symptoms including cough and with a reduction in his Prednisone dose. After 2 injections of benralizumab, his IgG4 level was $15.2 \mathrm{~g} / \mathrm{L}$, and his sputum eosinophil level was $0 \%$, but his FeNO remained high (96 ppb). Haemoglobin, creatinine, direct bilirubin and $\mathrm{IgG}$ levels had improved. His IgG4 level, after 4 injections of antiIL-5 $\mathrm{R} \alpha$ had been administered and the prednisone dose had been tapered to $15 \mathrm{mg}$ daily, was 11.2 . His symptoms remained almost completely relieved.

IgG4-RD is a recently recognized systemic disease. The median age of disease onset is between 61 and 70 years, and IgG4-RD predominates in males. Respiratory symptoms, including cough, exertional dyspnoea and chest pain, have been described in approximately one-half of patients with pulmonary IgG4-RD (17). It is commonly known that asthma often coincides with IgG4-RD (18-20). Two cohort studies $(21,22)$ reported that cough was the main symptom of IgG4-related pulmonary disease. Nine case reports (18-20,23-28) showed that 11 patients ( 7 males and 4 females) with IgG4-RD had prolonged cough, with seven of them showing cough for over 1 year $(18-20,23,24,27,28)$. Eosinophils were reported in 7 cases $(18,19,23,25-28)$. In some cases (24), cough relieved by prednisone but recurred following corticosteroid discontinuation. At the 11th Japan Cough Symposium, Toyoshima Mikio (29) presented a lecture entitled "Is IgG4-related disease a cause of chronic cough?" during which he reported two cases of IgG4-RD with chronic cough for which Treg hyperreactivity was considered the underlying pathogenic driver of this disease. Although blood eosinophilia is common in IgG4-RD, airway eosinophilia has seldom been reported. Zhang et al. classified IgG4-RD into two subtypes on the basis of clinicopathological characteristics (30): proliferative and fibrotic. Patients with the proliferative subtype tend to have high serum concentrations of IgG4 and $\operatorname{IgE}$, hypocomplementemia, peripheral eosinophilia, and multi-organ disease, often accompanied by atopy and excellent response to treatment. Our case was consistent with the proliferative subtype and showed a good response to benralizumab, a new anti-eosinophil biologic agent. IL-5 R $\alpha$ as a treatment target for IgG4-RD with eosinophilia has not been previously reported (30,31). IgG4-RD is considered a Th2-predominant disease (32). Recent advances in this field have clarified the importance of $\mathrm{T}$ follicular helper cells (33); $\mathrm{T}$ follicular helper cells play a key role in the disease process through IgG4 class switching, plasmablast and plasma cell differentiation, and germinal centre formation. The role of eosinophil granulocytes in IgG4$\mathrm{RD}$ has also attracted increasing interest (34). In IgG4$\mathrm{RD}$, peripheral eosinophilia increases with increasing sIgG4, and the presence of higher sIgG4 levels adds diagnostic value (35). However, the role of eosinophils in IgG4-RD remains unknown.

\section{Occupational eosinophilic bronchitis}

Occupational nonasthmatic eosinophilic bronchitis (NAEB) is characterized by the presence of chronic cough (lasting more than 3 weeks) that worsens at work and sputum eosinophilia [2.5\% (36) or 3\% (37) in the sputum], no evidence of airflow obstruction, AHR and normal PEF variability. Like occupational asthma, occupational NAEB may arise from occupational exposure. Occupational NAEB has been diagnosed after exposure to various agents or sensitizers, such as acrylates, natural rubber latex, mushroom spores, lysozyme, epoxy resin hardener, water-based metalworking fluids, isocyanate, flour and bucillamine (36-39). Most occupational eosinophilic bronchitis cases described in the literature came from Europe and United State. In Asia, only Japanese researchers reported tetrahydrophthalic anhydride (40) and mushroom spores (41) were causative agents. Occupational NAEB patients do not have wheezing and dyspnoea, typically present in middle age, both male and female, with dry cough or a cough productive of small amounts of sputum. The upper airway symptoms are common, but smoking is unusual. The examination of induced sputum should be used in addition to the monitoring of spirometry and AHR for workers who have chronic cough in an occupational setting. The work-related change in sputum eosinophilia and FENO are related to exposure to the offending agent and confirms that this is occupational NAEB. Cough reflex to capsaicin increased. A proposed set of criteria for the diagnosis of occupational eosinophilic bronchitis was developed by Santiago Quirce (36), including (I) isolated chronic cough (lasting more than 3 weeks) that worsens at work; (II) sputum eosinophilia $42.5 \%$ in either spontaneous or induced sputum; (III) increases in sputum eosinophilia are related to exposure to the offending agent (either at work or after specific inhalation challenge in the laboratory); (IV) spirometric 
parameters are within normal limits and are not significantly affected by exposure to the offending agent; (V) absence of airway hyperresponsiveness to methacholine (PC20 $416 \mathrm{mg} / \mathrm{mL}$ ) both at work and away from work; 6 . Other causes of chronic cough are ruled out. Once diagnosis has been established, exposure of the patient to the offending agent should completely stop. Unfortunately, it is not always possible for patients to spot exposure as employment opportunities carrying the same payment and job satisfaction may not be available. ICS treatment is almost invariably effective for cough and airway eosinophilia (42). It is not known why these patients do not have airway hyperresponsiveness despite the eosinophilic bronchial inflammation. Whether eosinophilic bronchitis can progress to typical occupational asthma remains unclear.

In summary, when evaluating patients with eosinophilia and chronic cough, determining the mechanism of airway eosinophilic inflammation may be difficult. The role of eosinophils as effector cells or bystanders in these conditions requires further research. The diagnosis and management of uncommon causes of chronic cough associated with airway eosinophilia requires frequent reevaluation, multidisciplinary discussion.

\section{Acknowledgments}

Funding: This work was supported by "Professor K.F. Chung's Visiting Professor Project of Guangzhou Institute of Respiratory Health (grant no.500102010501069001)". The funders had no role in study design, data collection and analysis, decision to publish, or preparation of the manuscript.

\section{Footnote}

Provenance and Peer Review: This article was commissioned by the editorial office for the series " 3 rd International Cough Conference" published in Fournal of Thoracic Disease. The article was sent for external peer review.

Conflicts of Interest: All authors have completed the ICMJE uniform disclosure form (available at http://dx.doi. org/10.21037/jtd-20-2324). The series "3rd International Cough Conference" was commissioned by the editorial office without any funding or sponsorship. KL serves as the unpaid Guest Editor of the series and serves as an unpaid editorial board member of Fournal of Thoracic Disease. KFC serves as the unpaid Associate Editors-in-Chief of Fournal of Thoracic Disease. The authors have no other conflicts of interest to declare.

Ethical Statement: The authors are accountable for all aspects of the work in ensuring that questions related to the accuracy or integrity of any part of the work are appropriately investigated and resolved.

Open Access Statement: This is an Open Access article distributed in accordance with the Creative Commons Attribution-NonCommercial-NoDerivs 4.0 International License (CC BY-NC-ND 4.0), which permits the noncommercial replication and distribution of the article with the strict proviso that no changes or edits are made and the original work is properly cited (including links to both the formal publication through the relevant DOI and the license). See: https://creativecommons.org/licenses/by-nc-nd/4.0/.

\section{References}

1. Lalloo UG, Barnes PJ, Chung KF. Pathophysiology and clinical presentations of cough. J Allergy Clin Immunol 1996;98:S91-6; discussion S96-7.

2. Irwin RS, Curley FJ, French CL. Chronic cough. The spectrum and frequency of causes, key components of the diagnostic evaluation, and outcome of specific therapy. Am Rev Respir Dis 1990;141:640-7.

3. Diver S, Russell RJ, Brightling CE. Cough and Eosinophilia. J Allergy Clin Immunol Pract 2019;7:1740-7.

4. Corrao WM, Braman SS, Irwin RS. Chronic cough as the sole presenting manifestation of bronchial asthma. $\mathrm{N}$ Engl J Med 1979;300:633-7.

5. Gonlugur U, Gonlugur TE. Eosinophilic bronchitis without asthma. Int Arch Allergy Immunol 2008;147:1-5.

6. Park SW, Jangm HK, An MH, et al. Interleukin-13 and interleukin-5 in induced sputum of eosinophilic bronchitis: comparison with asthma. Chest 2005;128:1921-7.

7. Gibson PG, Zlatic K, Scott J, et al. Chronic cough resembles asthma with IL-5 and granulocytemacrophage colony-stimulating factor gene expression in bronchoalveolar cells. J Allergy Clin Immunol 1998;101:320-6.

8. Hsieh FH. Hypereosinophilic syndrome. Ann Allergy Asthma Immunol 2014;112:484-8.

9. Curtis C, Ogbogu P. Hypereosinophilic Syndrome. Clin Rev Allergy Immunol 2016;50:240-51.

10. Xie J, Zhang J, Zhang X, et al. Cough in hypereosinophilic 
syndrome: case report and literature review. BMC Pulm Med 2020;20:90.

11. Roufosse F, Heimann P, Lambert F, et al. Severe Prolonged Cough as Presenting Manifestation of FIP1L1PDGFRA+ Chronic Eosinophilic Leukaemia: A Widely Ignored Association. Respiration 2016;91:374-9.

12. Khoury P, Desmond R, Pabon A, et al. Clinical features predict responsiveness to imatinib in platelet-derived growth factor receptor-alpha-negative hypereosinophilic syndrome. Allergy 2016;71:803-10.

13. Klion AD, Noel P, Akin C, et al. Elevated serum tryptase levels identify a subset of patients with a myeloproliferative variant of idiopathic hypereosinophilic syndrome associated with tissue fibrosis, poor prognosis, and imatinib responsiveness. Blood 2003;101:4660-6.

14. Niimi A, Brightling CE, Dicpinigaitis PV. Cough in asthma is due to eosinophilic airway inflammation: a pro/ con debate. Lung 2014;192:33-8.

15. Matsumoto H, Niimi A, Tabuena RP, et al. Airway wall thickening in patients with cough variant asthma and nonasthmatic chronic cough. Chest 2007;131:1042-9.

16. Cools J, DeAngelo DJ, Gotlib J, et al. A tyrosine kinase created by fusion of the PDGFRA and FIP1L1 genes as a therapeutic target of imatinib in idiopathic hypereosinophilic syndrome. N Engl J Med 2003;348:1201-14.

17. Ryu JH, Sekiguchi H, Yi ES. Pulmonary manifestations of immunoglobulin G4-related sclerosing disease. Eur Respir J 2012;39:180-6.

18. Wang X, Wan J, Zhao L, et al. IgG4-related disease with tracheobronchial miliary nodules and asthma: a case report and review of the literature. BMC Pulm Med 2019;19:191.

19. Lee YS, Cho HJ, Yoo HS, et al. A case of IgG4-related disease with bronchial asthma and chronic rhinosinusitis in Korea. J Korean Med Sci 2014;29:599-603.

20. Sekiguchi H, Horie R, Aksamit TR, et al. Immunoglobulin G4-related disease mimicking asthma. Can Respir J 2013;20:87-9.

21. Suzuki R, Yi E, Ryu J, et al. IgG4-Related Lung Disease: Retrospective Review of 9 Cases. CHEST 2016;150:1068A.

22. Sun X, Liu H, Feng R, et al. Biopsy-proven IgG4-related lung disease. BMC Pulm Med 2016;16:20.

23. Monach PA, Stone JH, Sharma A, et al. Case 6-2017. A 57-year-old woman with fatigue, sweats, weight loss, headache, and skin lesions. N Engl J Med 2017;376:775-86.

24. Hui P, Mattman A, Wilcox PG, et al. Immunoglobulin G4-related lung disease: a disease with many different faces. Can Respir J 2013;20:335-8.

25. Slim D, Gunawardena H, Calvert JM, et al. IgG4-related pulmonary disease: the protean impersonator? J R Coll Physicians Edinb 2018;48:130-3.

26. Mahgoub A, Daouk A, Abou Yassine A, et al. A Case of IgG4-Related Disease Causing Eosinophilic Pleural Effusion and Cardiac Tamponade. Chest 2017;152:A906.

27. Pattison R, Akiode O, Perez-Guerra F, et al. IgG4 Related Disease Emerging. Chest 2015;148:869A.

28. Chen CF, Chu KA, Tseng YC, et al. IgG4-related lung disease presenting as interstitial lung disease with bronchiolitis: A case report. Medicine (Baltimore) 2017;96:e9140.

29. Mikio T. Is IgG4-related disease a cause of chronic cough? The 11th Japan Cough Symposium 2009.

30. Zhang W, Stone JH. Management of IgG4-related disease. Lancet Rheumatol 2019;1:e55-e65.

31. Kuang FL, Klion AD. Biologic Agents for the Treatment of Hypereosinophilic Syndromes. J Allergy Clin Immunol Pract 2017;5:1502-9.

32. Moriyama M, Nakamura S. Th1/Th2 Immune Balance and Other T Helper Subsets in IgG4-Related Disease. Curr Top Microbiol Immunol 2017;401:75-83.

33. Akiyama M, Suzuki K, Yasuoka H, et al. Follicular helper T cells in the pathogenesis of IgG4-related disease. Rheumatology (Oxford) 2018;57:236-45.

34. Della Torre E, Mattoo H, Mahajan VS, et al. Prevalence of atopy, eosinophilia, and IgE elevation in IgG4-related disease. Allergy 2014;69:269-72.

35. Mohapatra S, Charilaou P, Sharma A, et al. Significance of peripheral eosinophilia for diagnosis of IgG4-related disease in subjects with elevated serum IgG4 levels. Pancreatology 2020;20:74-8.

36. Quirce S. Eosinophilic bronchitis in the workplace. Curr Opin Allergy Clin Immunol 2004;4:87-91.

37. Sastre J. Occupational nonasthmatic eosinophilic bronchitis. Revue Française d'Allergologie 2010;50:285-7.

38. Wiggans RE, Barber CM. Metalworking fluids: a new cause of occupational non-asthmatic eosinophilic bronchitis. Thorax 2017;72:579-80.

39. Di Stefano F, Di Giampaolo L, Verna N, et al. Occupational eosinophilic bronchitis in a foundry worker exposed to isocyanate and a baker exposed to flour. Thorax 2007;62:368-70.

40. Kobayashi O. A case of eosinophilic bronchitis due to epoxy resin system hardener, methle endo methylene tetrahydro phthalic anhydride. Arerugi 1994;43:660-2.

41. Tanaka H, Narita M, Teramoto S, et al. Role of 
interleukin-18 and T-helper type 1 cytokines in the development of Mycoplasma pneumoniae pneumonia in adults. Chest 2002;121:1493-7.

42. Gibson PG, Hargreave FE, Girgis-Gabardo A, et al.

Cite this article as: Xie J, Chung KF, Lai K. Uncommon causes of chronic cough associated with airway eosinophilia. J Thorac Dis 2021;13(5):3191-3196. doi: 10.21037/jtd-20-2324
Chronic cough with eosinophilic bronchitis: examination for variable airflow obstruction and response to corticosteroid. Clin Exp Allergy 1995;25:127-32. 